\title{
SÍNTOMAS DE UNA ÉPOCA: MAGNETISMO, HISTERIA Y ESPIRITISMO EN LA ALEMANIA ROMÁNTICA*
}

\author{
Luis Montiel \\ Universidad Complutense. Madrid
}

\section{RESUMEN}

Centrándose en el análisis de tres casos especialmente significativos se pretende comprender el significado histórico del encuentro en la Europa de comienzos del siglo XIX de una teoría médica - el magnetismo animal - un peculiar sistema de creencias —el espiritismo- y una enfermedad ya conocida, pero que comenzará a contemplarse con una mirada nueva: la histeria. Serán, por otra parte, la enfermedad y la teoría médica quienes den alas a ese sistema de creencias y permitan su despliegue en el seno de la cultura occidental, afirmándose frente a otras concepciones del mundo y mostrando, con ello, las insuficiencias de estas últimas.

PALABRAS CLAVE: Magnetismo animal, histeria, espiritismo, Romanticismo, historia clínica.

\begin{abstract}
By centring on an analysis of three particularly significant cases, the article seeks to understand the historical meaning of the encounter in early 19th-century Europe between a medical theory - mesmerism - a peculiar system of beliefs — spiritualism — and an already known disease, but which was to be seen from a new perspective: hysteria. Moreover, the disease and the medical theory are the elements that made this system of beliefs flourish and enabled it to take hold in the core of Western culture, affirming itself over other conceptions of the world and showing, with this, the insufficiencies of the latter.
\end{abstract}

KEY WORDS: Mesmerism, hysteria, spiritualism, romanticism, clinical history.

* Proyecto HUM2004-00777. 


\section{UN TRÍO POCO RECOMENDABLE}

La histeria es una enfermedad antigua. Casi tan antiguo como ella es el término que la nombra. Ambos han recorrido un largo trecho hasta llegar a asociarse entre sí del modo que hoy consideramos válido, y son numerosas las obras que han intentado dar cuenta de esa historia ${ }^{1}$. Uno de sus jalones se ha visto privilegiado por nuestra propia perspectiva: la etapa en la que la proteica enfermedad se convirtió en centro de interés del fundador de la neurología, Jean-Martin Charcot, a la que siguió inmediatamente aquella en la que Sigmund Freud se sirvió de dicha enfermedad para acceder a su influyente concepción de la vida psíquica inconsciente. Todo esto es de sobra conocido². Pero el caso es que la parte de la obra de Charcot relativa a esta materia no podría entenderse sin tener en cuenta la existencia previa de unos hechos y de un ambiente intelectual que propiciaron la aparición —o si se prefiere, la aparición «en escena»- de un tipo muy caracterizado de paciente, así como el interés de los médicos por el estudio experimental, o al menos casuístico, de determinados fenómenos: los denominados primero sonambúlicos, luego hipnóticos. Así, las historias de la histeria y del magnetismo animal -luego hipnotismo - discurren asociadas a lo largo de casi todo el siglo XIX.

Otro tanto sucede con el espiritismo. La creencia en espíritus desencarnados, ya sean emanaciones de la divinidad, visitantes de ultratumba o emisarios del Maligno ${ }^{3}$ es seguramente tan antigua como el homo sapiens; pero su

1 Sin pretensión alguna de exhaustividad mencionaré las siguientes: VEITH, I. (1965). Hysteria: The History of the Disease. Chicago, University of Chicago Press. TRILlat, E. (1986). Histoire de l'hystérie. Paris, Seghers. MiCAlE, M. S. (1995) Approaching Hysteria. Disease and its Interpretations. Princeton, Princeton University Press. EdELman, N. (2003). Les métamorphoses de l'hystérique. Du début du XIXe siècle à la Grande Guerre. Paris, La Découverte.

2 Cfr. Lopez PiÑero, J.M.; Morales Meseguer, J.M. (1970). Neurosis y psicoterapia: un estudio histórico. Madrid, Espasa Calpe. EllenBerger, H.F. (1976). El descubrimiento del inconsciente. Historia y evolución de la psiquiatría dinámica. (Trad. esp.) Madrid, Gredos. Lopez PiÑERo, J.M. (2002). Del hipnotismo a Freud. Orígenes históricos de la psicoterapia. Madrid, Alianza Editorial. MÉHEust, B. (1999). Somnambulisme et médiumnité (2 vol.). Le Plessis Robinson, Institut Synthélabo. Montiel, L.; GonZalez DE PABLO, A. (2003). En ningún lugar, en parte alguna. Estudios sobre la historia del magnetismo animal y del hipnotismo. Madrid, Frenia.

3 Sobre el significado de la figura del fantasma, en el sentido de muerto que vuelve de la tumba para comunicarse con los vivos véase: SCHMITT, J-C. (1994). Les vivants et les morts dans la société médiévale. Paris, Gallimard; a mi parecer, el hecho de estar centrado en la Edad Media no le resta ningún valor para comprender el fenómeno en períodos más recientes. Sobre la figura 
camino se encuentra de manera singular con el del magnetismo animal precisamente en la etapa en que éste se topa con el de la histeria ${ }^{4}$.

Este singular encuentro ha servido, prácticamente desde el momento mismo en que tuvo lugar, para descalificar a la teoría médica inventada por Mesmer. No en vano histeria y espiritismo son conceptos cargados de connotaciones negativas en nuestra cultura, por más que el segundo de ellos, como es sabido, gozaría de una peculiar edad de oro en el fin-de-siècle. Así, el magnetismo animal, hasta ser «rescatado» — ¡rescatado como estado patológico! - por el hipnotismo médico, viose descalificado no sólo por su inconsistencia científica — según los criterios de la ciencia experimental- sino también por andar en malas compañías.

Sin embargo, desde un punto de vista que pretende ser más ecuánime, esa misma liaison dangereuse hace a esas tres realidades especialmente interesantes, pues, en la medida en que dejaron su huella - una huella muy profundaen la sociedad decimonónica, podrían ser consideradas, en el peor de los casos, síntomas de un malestar que recorre la época apoderándose de ella en la figura de quienes son más sensibles a sus tensiones, a sus contradicciones, a sus incongruencias. Adelanto que no es mi pretensión diagnosticar patología alguna a través de tales síntomas, sino solamente caracterizarlos y comprenderlos con la mayor claridad posible. Dado que fue el magnetismo animal quien permitió salir a la luz tanto a la histeria como al espiritismo con un vi-

del Diablo y los demonios, y sobre las consecuencias de representar el mal bajo una figura singular o bajo las de un pandaemonium véase TAusiet, M. (2004). Ponzoña en los ojos. Brujería y superstición en Aragón el el siglo XVI. Madrid, Turner, especialmente pp. 258-259.

4 Como queda señalado en la nota anterior, el fantasma entendido como revenant tiene una historia notablemente más antigua. En lo que concierne a Alemania (aunque creo que la tesis que mencionaré podría muy bien aplicarse a otros países europeos, salvando las diferencias religiosas), Sawicki ha demostrado que el discurso religioso de las últimas tres décadas del siglo XVIII actualizó involuntariamente la creencia en fantasmas al esforzarse en mostrar a los fieles el más allá no como algo lejano, sino como un reino poblado por espíritus entre los que se contaban los de sus deudos. SAWICKI, D. (2002). Leben mit den Toten. Geisterglauben und die Entstehung des Spiritismus in Deutschland 1770-1900. Paderborn, Schöningh, 41-47. En las páginas 13-20 de esta misma obra puede encontrar el lector una sugerente explicación acerca de la aparición de «los espíritus» a partir del discurso sobre «el Espíritu», así como acerca de las propiedades paulatinamente atribuidas a aquellos a medida que avanza el discurso espiritista. De este modo, Sawicki data el nacimiento del espiritismo en Alemania bastante más temprano que Nicole Edelman, y lo considera un producto autóctono, si bien es cierto que la tesis de la autora francesa —origen estadounidense y entronización en Europa a través de Allan Kardec- es acertada en cuanto a su consolidación y conversión en fenómeno de masas. Cfr. Edelman, N. (2006). Histoire de la voyance et du paranormal du XVIII siècle à nos jours. Paris, Seuil, 66, y el artículo incluido en este dossier. 
gor hasta entonces desconocido, y concediéndoles además un crédito del que, hasta entonces, no habían gozado, él será el eje de este trabajo.

\section{CAMBIO DE ÉPOCA}

La Revolución Francesa —o más exactamente, la corriente subterránea que se manifestó de manera volcánica en ella - trajo consigo numerosos cambios en el sentido del progreso, entendido a la manera occidental; pero también acarreó algunos que podrían considerarse retrógrados. Tal es el caso del magnetismo animal. Cierto es que su éxito se produjo antes de que la Revolución propiamente dicha estallase. Pero no lo es menos que el propio Mesmer tuvo buenos amigos entre los revolucionarios y que, en alguna medida, su obra y su persona estuvieron presentes en diversas tentativas, logradas o fallidas, de cambio político y social ${ }^{5}$, así como que el éxito de la nueva terapéutica se mantuvo contra viento y marea durante las primeras décadas del siglo XIX. En este sentido resulta extraordinariamente interesante el testimonio de un conservador cualificado, como fue Goethe ${ }^{6}$, quien, en una carta al influyente médico y naturalista Nees von Essenbeck, escribió:

Si pienso que, en el período más activo de mi vida, Gassner y Mesmer hicieron tanto ruido y tuvieron tantos seguidores, y que fui amigo de Lavater, que tenía una consideración religiosa de este fenómeno natural [el magnetismo animal], me parece muy raro no haberme sentido atraído y que al contrario tuviera la actitud de alguien que camina a lo largo de la orilla de un río sin que le vengan ganas de bañarse ${ }^{7}$.

En su olímpico retiro de Weimar Goethe nunca dejó de ser un ilustrado. Recuérdese su conocida preferencia por lo «objetivo, sano y clásico» frente a lo «sentimental, patológico y romántico». Así, aunque su interés de científico debía moverle hacia el estudio del magnetismo animal, su probado instinto de conservación le llevó a no bañarse nunca en un río que juzgaba peligroso.

5 Montiel, L. (2006 a). «Magnetismo romántico. El paciente. La mujer. La república». DYNAMIS, 26, 125-150 (143-145).

6 Para los lectores españoles basta con recordar su aplauso a la iniciativa de la Santa Alianza de enviar a España a los Cien Mil Hijos de San Luis, del que Eckermann nos dio cuenta en sus célebres Conversaciones.

7 Carta del 23 de julio de 1820, cit. por BARKHOFF, J. «Silenzio eloquente e sottile ellaborazione letteraria: Goethe e il mesmerismo». En: FrIGO, G.F.; SimILI, R.; VERCELlONE, F.; von EngelhardT, D. (2005). Arte, scienza e natura in Goethe. Torino, Trauben, 11-27 (12). 
Pero lo cierto es que la teoría tenía algo, como prueba la actitud de Goethe que Jürgen Barkhoff ha calificado de «silencio elocuente»: en este caso el Júpiter de Weimar no se atreve a tronar ${ }^{8}$.

Hay motivos para elegir el silencio. En la cita precedente se menciona al unísono al fundador de la doctrina del magnetismo animal y a Gassner; pero no puede olvidarse en qué circunstancias se cruzaron sus nombres: Gassner, religioso, practicaba curas mediante el exorcismo, convencido de que las enfermedades que curaba eran de origen demoníaco; y Mesmer dictaminó - lo que le valió ser nombrado miembro de la Academia de Ciencias de Baviera, y referencia obligada en los periódicos alemanes defensores de la Aufklärungque la religión no tenía nada que ver en ello, y que era una fuerza natural —el magnetismo animal - quien producía las curaciones ${ }^{9}$. Tampoco hay que olvidar que su concepción de esta fuerza era unilateralmente materialista, dejando de lado cualquier consideración psicológica, lo que, entre otras cosas, le llevó a no prestar atención alguna a la positiva interpretación del sonambulismo magnético propuesta por Puységur. En dicha perspectiva Mesmer era, desde luego, más «moderno» que Gassner. En descargo de Goethe hay que decir que el camino que conduce, en Alemania, de Mesmer a Justinus Kerner, y que a continuación recorreremos, desemboca, paradójicamente, en un reencuentro con las creencias del desprestigiado clérigo. Y el lector no debe pensar que se trata sólo de un camino local pues, aunque en otros países europeos el magnetismo y el espiritismo tengan una presencia singular, la influencia de Kerner en los círculos espiritistas no alemanes a través de su célebre libro sobre la Vidente de Prevorst, del que me ocuparé aquí, será fundamental.

\section{EL LADO NOCTURNO DE LAS CIENCIAS NATURALES.}

La Naturphilosophie de Schelling, con su reivindicación de la unidad indisoluble de materia y espíritu ${ }^{10}$, abrió las puertas al estudio del «lado nocturno

8 Este silencio no puede pasarse por alto si se compara, por ejemplo, con lo audaz de su apuesta en la Teoría de los colores: demostrar, nada menos, que la teoría óptica de Newton era errónea. Pero, como muestra el estudioso alemán, Goethe tratará el tema de manera menos comprometida, en tanto que literaria, en su novela Las afinidades electivas.

9 EGO, A. (1991). Animalischer Magnetismus oder Aufklärung. Eine mentalitätsgeschichtliche Studie zum Konflikt um ein Heilkonzept im 18. Jahrhundert. Würzburg, Königshausen \& Neumann, 1-27.

10 Recuérdese su taxativa afirmación en el prólogo a los Jahrbücher der Medizin als Wissenschaft: «La naturaleza debe ser espíritu visible y el espíritu, naturaleza invisible». Cfr. 
de la ciencia natural». Con el término «lado nocturno» - Nachtseite- denominó Gotthilf Heinrich Schubert aquellas zonas de la naturaleza que no podían ser investigadas con los medios habituales de la pesquisa cientificonatural, la observación y el experimento, y que por tanto requerían de otros métodos: la especulación y la analogía. La serie de conferencias que pronunció en Dresde sobre este asunto, significativamente tituladas Opiniones sobre el lado nocturno de la ciencia natural, publicadas luego como libro ${ }^{11}$, dejaron una huella fácil de reconocer en la obra de no pocos autores de la época, como E.T.A. Hoffmann, Heinrich von Kleist, Jean Paul y Achim von Arnim y marcaron un estilo de trabajo para muchos seguidores de la Naturphilosophie ${ }^{12}$. De hecho Schelling pareció delegar de algún modo en su siempre fiel amigo Schubert el cuidado de desarrollar esta rama de su ambiciosa ciencia del todo, a la que desde luego él mismo nunca renunció, como pone de manifiesto su publicación a la muerte de su esposa, acaecida en 1809, de Clara, o sobre la conexión de la naturaleza con el mundo de los espíritus ${ }^{13}$, obra fuertemente influenciada por el magnetismo animal y con evidente contenido espiritista.

Prácticamente no hubo Naturphilosoph que no cultivara esa Nachtseite der Naturwissenschaft, profundizando en esta dimensión desconocida de la ciencia de la naturaleza. El magnetismo animal, sobre todo después de verse modificado por Puységur, quien concedía la mayor importancia al sonambulismo o «sueño lúcido», parecía ofrecer un instrumento especialmente adecuado para esa pesquisa ${ }^{14}$. Fueron los Naturphilosophen quienes intentaron rescatar

Arquiola, E.; Montiel, L. (1993). La corona de las ciencias naturales. La medicina en el tránsito del siglo XVIII al XIX. Madrid, CSIC, 104-108.

11 SCHUBERT, G.H. (1808). Ansichten von der Nachtseite der Naturwissenschaften. Dresden, Arnold.

12 BARKhoff, J. (1995) Magnetische Fiktionen. Literarisierung des Mesmerismus in der Romantik. Stuttgart, Metzler, 100.

13 Clara oder über den Zusammenhang der Natur mit der Geisterwelt. (1810)

14 De entre los autores considerados como clásicos en el estudio del Romanticismo he seleccionado estos testimonios: HuCH, R. [1924] (1978-79). Les romantiques allemands. Aixen-Provence, Pandora, vol II., p.226: «Vinculada ya al romanticismo por la Filosofía de la Naturaleza, la medicina se convirtió definitivamente en una ciencia romántica al apoderarse del mesmerismo o magnetismo animal». BEGUIN, A. [1939] (1981) El alma romántica y el sueño. México, Fondo de Cultura Económica, p. 91: «Las curas magnéticas tuvieron una popularidad inaudita, y los filósofos de los salones o de las facultades tuvieron un magnífico campo de disputas, hipótesis descabelladas y explicaciones enrevesadas». GuSDORF, G. (1993). Le romantisme. Paris, Payot, vol II, p. 534: «El magnetismo animal, contribución fundamental a la inteligibilidad romántica...». La declaración más contundente al respecto pertenece al auténtico iniciador del estudio sobre la medicina del Romanticismo alemán, Wer- 
a Mesmer de su voluntario ostracismo en Frauenfeld ${ }^{15}$, y fueron ellos también quienes hicieron vivir al magnetismo animal su segunda edad de oro. Dados los objetivos del presente trabajo me limitaré a tratar solamente aspectos muy concretos de su práctica y de la teoría que unas veces se encontraba en su base, y otras surgía de la experiencia clínica.

Tanto la teoría como la práctica del magnetismo animal romántico parecían confirmar la mayor capacidad magnética de la mujer sobre el varón. Especialmente en un autor como Dietrich Georg Kieser, que formuló con minucia la teoría de la polaridad de la naturaleza presente ya en la obra de Schelling, y que fue uno de los más exigentes estudiosos del magnetismo animal, se observa esta asociación entre lo femenino, lo nocturno y lo magnético en las obras teóricas ${ }^{16}$; pero también en sus publicaciones clínicas llama la atención la casi absoluta ausencia de pacientes varones ${ }^{17}$. Este último dato no es privativo, como veremos - y como muestra la bibliografía casuística circulante - de dicho autor.

De este modo, la mujer llega a ocupar, sin habérselo propuesto, un lugar de preeminencia en el seno de una teoría polémica que apasiona por igual a defensores y detractores. Ya desde la época de Mesmer se sabía que el magnetismo animal se revelaba especialmente eficaz en los trastornos nerviosos, por lo que no es de extrañar que la mayor demanda terapéutica provenga de mujeres cuyos síntomas no pueden ser contrarrestados por los médicos que emplean los remedios al uso y que muy a menudo los etiquetan de «histéricos», o los interpretan como resultado de furor uterinus o nymphomania,

ner Leibbrand: «Sin el magnetismo animal, el romanticismo médico no habría llegado a ser más que un torso». LEIBBRAND, W. (1956). Die spekulative Medizin der Romantik. Hamburg, Claasen, 174.

15 La historia de este renacimiento, que conocemos a través de diversas fuentes, ha sido puesta al día por Walter Artelt. Cfr. ARTELT, W. (1965). «Der Mesmerismus in Berlin». Akademie der Wissenschaften und der Literatur in Mainz, Abhandlung des geistes- und sozialwissenschaftlicher Klasse, vol. 6, 390-473. A partir de este texto, complementándolo con la lectura de otras aportaciones más recientes, la he relatado en castellano en: MonTIEL, L. (2006 b). Daemoníaca. Curación mágica, posesión y profecia en el marco del magnetismo animal romántico. Barcelona, MRA, 24-32.

16 KIESER, D.G. (1817-1819). System der Medicin zum Gebrauche bei akademischen Vorlesungen und für practische Ärzte. 2 Bd.. Halle, Hemmerde und Schwertschke. KIESER, D. G. (1822, 1826). System des Tellurismus oder thierischer Magnetismus. 2 Bd. Leipzig, Herbig.

17 Hay que exceptuar a Anton Arst, si bien éste era un niño cuando Kieser se hizo cargo de su tratamiento, del que da cuenta en la revista de la que era editor: KIESER, D.G. (1818). «Geschichte eines durch das unmagnetisierte baquet allein erzeugten Somnambulismus und hierdurch geheilter Epilepsie». Archiv für den thierischen Magnetismus, III- 2, 50-160 
otros tantos sinónimos del primer término ${ }^{18}$. Pero además la situación de estas pacientes en manos de los magnetizadores es extremadamente diferente, radicalmente nueva, y desde luego muy favorable: dado que se considera que en el estado sonambúlico se pone de manifiesto un cierto saber del cuerpo sobre sí mismo - son moneda común el autodiagnóstico y la autoprescripción terapéutica-, el médico debe renunciar a su conocida posición de poder, pues ya no es él quien detenta el saber que antaño se le reconocía. Ahora debe ser solamente auxiliar de la naturaleza, que manifiesta su Nachtseite a través del sueño, y sobre todo de ese sueño de calidad singular que es el sueño magnético. De este modo, es el paciente - por lo general la paciente- quien toma las riendas de su tratamiento, situación que sin duda constituía uno de los puntos más sensibles de la teoría y la práctica magnéticas para el cuerpo médico en su conjunto.

A continuación presentaré tres casos estudiados en el contexto del magnetismo animal romántico que considero ejemplares desde el punto de vista que orienta este trabajo. Los dos procedentes de la pluma de Justinus Kerner son conocidos — uno más que el otro: el de la célebre Vidente de Prevorst- aunque, en el mejor de los casos, sólo en el ámbito de los estudios relativos a la medicina romántica alemana o en el de los que se ocupan de los orígenes del espiritismo $^{19}$. El publicado por Kieser no ha sido, si mis noticias son correctas, objeto de estudio hasta el presente. Por razones cronológicas éste será el primero del que me ocupe.

18 Especialmente ejemplar en este sentido es el caso que actualmente estudiamos un pequeño grupo de investigadores franceses y yo mismo: el tratamiento magnético llevado a cabo en París por el médico y magnetizador alemán David Ferdinand Koreff y su colega polaco Wolowski en la persona de lady Susan Lincoln. Cfr. MonTIEL, L. (2006 a), 140-142.

19 Cfr. Berger-FiX, A. (Hrsg.) (1986) Nur wenn man von Geistern spricht. Briefe und Kleksographien. Stuttgart-Wien, Thienemann, especialmente los capítulos de SCHOTT, H. «Der 'Okkultismus' bei Justinus Kerner- Eine medizinhistorische Untersuchung (71-103) у BAUER, E. «Kerner und die Parapsychologie» (105-123), así como los cuatro trabajos comprendidos bajo la explícita rúbrica «Okkultismus und Geisterkunde» en ScHOTT, H. (Hrsg.) (1990). Justinus Kerner. Jubiläumsband zum 200 Geburtstag. Teil 2, Medizin und Romantik. Kerner als Arzt und Seelenforscher. Weinsberg, Nachrichtenblatt der Stadt Weinsberg (BREMAYER, R. «Vom Weinsberger Dekan Friedrich Christoph Oetinger zu Justinus Kerner: Theosophische Traditionen», 295-310; SHIMBO, S. «Kerners Parapsychologie im Lichte der JungStillinschen Geisterkunde», 311-320; BAUER, E. «Kerner als Spukforscher», 321-333; JENNINGS, L.B. «Justinus Kerner: Spätromantiker und früher parapsychologe», 324-339). Finalmente incluso las revistas dedicadas al estudio de la parapsicología han reparado en la figura de este autor. Un ejemplo: BRÜNING, R. (1998/1999). «Justinus Kerner und der Spuk im Gefängnis zu Weinsberg (1835/36). Oder von der Schwierigkeit, einem Geist amtlich beglaubigen zu lassen». Zeitschrift für Parapsychologie und Grenzgebiete der Psychologie, 40/41, 41-60. 


\section{LA MUCHACHA MARAVILLOSA DE JOHANNGEORGENSTADT}

Aunque publicado por Kieser en su Archiv für den thierischen Magnetismus, este caso no procede de su propia práctica. Se trata de la transcripción, seguida de un breve esbozo de interpretación, de dos informes acerca de un hecho singular en el que el magnetismo animal se empleó, con dudoso éxito, como terapia, por tener los circunstantes la convicción de que los fenómenos observados eran de carácter «magnético». El texto lleva por título: «La muchacha maravillosa de Johanngeorgenstadt» y se publicó en el Archiv en $1820^{20}$. La lectura del mismo permite comprender que el asunto al que se refiere tuvo un interés preponderantemente social, y más concretamente religioso, en cierta medida relacionado con el orden público, representando la medicina un papel secundario, al menos aparentemente. La prueba más evidente de ello es que el primero de los documentos publicados es el informe redactado por un clérigo, mientras que el segundo, escrito por «el médico municipal y de las minas de Johanngeorgenstadt» ${ }^{21}$, lleva, pese a su extensión — doce páginas del Archiv - el poco pretencioso título de «carta» y parece presentarse como un mero apéndice, como una especie de informe pericial destinado a suministrar argumentos al autor del escrito principal. Sin embargo, esa relación jerárquica, que parece aceptada sin ambages por el autor de la carta, el doctor Gruber, es menos clara de lo que podría parecer, pues el eclesiástico afirma su autoridad para juzgar el fenómeno precisamente apoyándose en la medicina. Lo que ocurre es que, al tratarse de un fenómeno de índole religiosa, el reparto de papeles no parece haber sido cuestionado por ninguno de los participantes. No obstante, el hecho de que ambos documentos interesen a los editores del Archiv, y que concretamente Kieser los interprete desde una perspectiva que no es exclusivamente «magnética», sino también psicológica, muestra claramente hasta qué punto la medicina se siente capacitada para reclamar para su estatuto este tipo de fenómenos, propiedad exclusiva de la religión hasta fechas recientes. Y uno de los aspectos más interesantes del caso es que, como veremos, si bien por una parte el magnetismo animal da argumentos a la autoridad religiosa para desactivar, si así puede decirse, una especie de carga explosiva social, por otra permite el total despliegue del discurso subversivo que constituye el núcleo de la enfermedad. La lectura secuencial de los dos escritos originales resulta muy aleccionadora, pues permi-

20 KIESER, D. G. (1820 a) «Das wunderbare Mädchen in Johanngeorgenstadt». Archiv für den thierischen Magnetismus, 8 (1), 48- 86.

21 KIESER, D.G. (1820 a), 69-80. 
te descubrir lo que el religioso pasa por alto aunque interese, y mucho, al médico; pero por razones prácticas expondré ahora la historia basándome al unísono en ambos documentos 22 .

\subsection{Una enfermedad magnética}

La protagonista de la historia es Friederike Erdmuthe Reinhold, de 23 años, hija del maestro zapatero y alcalde de Johanngeorgenstadt, localidad minera situada en los Erzgebirge - Montes Metalíferos-, en Sajonia; éste, como veremos, es un dato que podría no carecer de relevancia para la comprensión del caso.

La muchacha nunca tuvo una salud muy firme, pues sufrió escrófulas - tuberculosis ganglionar - en la primera juventud y enfermedades de los ojos. En febrero de 1819 se declaró la enfermedad objeto de este escrito. Comenzó por un debilitamiento general, resultado de la pérdida de apetito y de trastornos digestivos, desembocando en un cuadro primero de calambres, luego de convulsiones que se transformaron en una auténtica epilepsia. Durante 18 semanas la enferma padeció estos horribles ataques casi a diario. Luego desaparecieron las convulsiones, pero — escribe el sacerdote- «los calambres adoptaron la forma de fenómenos sonambúlicos ${ }^{23}$, que se presentaban cada tres días, a horas diferentes; probablemente esta interpretación, aunque expresada por el pastor, proceda del médico, que en ese momento ya había sido llamado a consulta. El doctor Gruber consideró que los síntomas podían mejorar mediante el empleo del magnetismo animal, pero reconociéndose como un mero aficionado, decidió encomendar a la joven a los cuidados de una pariente prácticamente de su misma edad, Johanne Schlegel, también paciente suya, en la que ha descubierto extraordinarias dotes sonambúlicas. Por ejemplo, cuando, en el sueño magnético, solicitaba que se le practicase una sangría, dejaba espontáneamente de sangrar en el momento exacto en que terminaba de salir de sus venas la cantidad prevista, sin necesidad de hemostasia ${ }^{24}$.

Apenas es preciso señalar la novedad que representa esta delegación de responsabilidades - y de poderes - por parte del médico, no del todo infrecuente en el marco del magnetismo animal, aunque pocas veces tan explícita e incondicional. Durante algunos días Johanne Schlegel magnetizó a Friede-

\footnotetext{
22 El lector puede encontrar el resultado de la otra lectura en MoNTIEL, L. (2006 b), 106-117.

23 KIESER, D.G. (1820 a), 50.

24 KIESER, D.G. (1820 a), 69.
} 
rike Reinhold, consiguiendo una notable atenuación de los síntomas de su enfermedad. La descripción que de tal tratamiento realiza el doctor Gruber es muy interesante, pues pone de manifiesto algunas verdades ocultas que se manifiestan - o más exactamente, se revelan a un lector actual- a través del lenguaje corporal, lo que ni el médico ni sus con temporáneos están en condiciones de comprender. He aquí la descripción: cuando Friederike comienza a sufrir convulsiones la joven Schlegel apoya sus manos sobre los hombros de aquella, tratando - interpreta académicamente el médico - de establecer el rapport magnético, cosa que consigue en unos cinco minutos, produciéndose entonces la crisis, que se manifiesta en este caso por la aparición del sueño. De la eficacia de este rapport da cuenta, a su parecer, el hecho de que los rasgos de la paciente muestran entonces una expresión jovial. Luego la Schlegel realiza algunas maniobras magnéticas que el doctor Gruber describe igualmente con términos técnicos - asperjar, ventilar-, y que seguramente ha aprendido de él, retirándose después de una imposición de manos. Entonces la paciente experimenta lo que se compara a una "sacudida eléctrica» y despierta. Después - prosigue Gruber - «las dos personas mutuamente magnetizadas» ${ }^{25} \mathrm{se}$ abrazan y se consuelan durante algunos minutos y rezan por la curación, tras de lo cual se intercambian pases magnéticos, dando así por concluida la sesión terapéutica. Como puede verse, las fronteras entre terapeuta y paciente son, en esta peculiar relación, absolutamente borrosas: una enferma «veterana», considerada además sonámbula natural, magnetiza a otra, más bisoña y «artificial» - pues Friederike no posee las dotes originales y supuestamente innatas de Johanne-, pero al final ambas protagonistas intercambian ayudas magnéticas, «consuelos» (Trostungen) y oraciones, siempre en el seno del estado magnético, es decir, en un estado que podríamos llamar «de responsabilidad limitada», que les concede una libertad de expresión inédita hasta la fecha.

El tratamiento se interrumpió por motivos extramédicos: el novio de la Schlegel, con el que, al cabo de poco tiempo, se casó, prohibió que la terapia siguiera adelante por sospechar que podía resultar contraproducente para su prometida. Probablemente este hecho acrecentó la inseguridad del doctor Gruber, quien parece, además, sentirse parcialmente responsable de la imprevista evolución de la enfermedad de Friederike por haber tomado esa arriesgada decisión ${ }^{26}$.

25 KIESER, D.G. (1820 a), 74

26 No es seguro, pero tal idea podría desprenderse del calificativo que él mismo da a la paciente: «enferma artificialmente magnética», o «enferma en la que el estado magnético se provoca artificialmente» (p. 72). Aunque el calificativo «künstlich»—artificial o técnico- no necesariamente presenta, en este contexto, connotaciones negativas. 
Precisamente esa evolución inesperada es lo que confiere toda su singularidad al caso de «la muchacha maravillosa de Johanngeorgenstadt». A partir de este punto conviene remitirse al relato del eclesiástico, pasando por alto sus comentarios de corte científico y sus referencias al magnetismo animal, para centrarse en lo fundamental: la fenomenología religiosa del discurso sonambúlico.

\subsection{La Salvadora de las mujeres}

Para ello hemos de volver al relato del párroco, más atento que el médico a este aspecto de la misteriosa enfermedad. En el curso de sus accesos convulsivos, o más exactamente cuando las convulsiones, y la ocasional parálisis de los músculos fonadores, cedían, aunque sin salir del denominado estado sonambúlico, la paciente se dirigía a Dios para decirle que no creía haber hecho algo que mereciera ese castigo. En un par de ocasiones se alzó del lecho para, de rodillas, prometer a Dios que rezaría por los hombres de fe tibia, que iría aplicadamente a la iglesia o que se apartaría del mundo, como si con ello pretendiera aplacar su cólera y verse así libre del inmerecido castigo. El efecto que estos parlamentos producían sobre quienes los escuchaban y, de manera indirecta, sobre la propia paciente, preocupó al sacerdote. En su opinión, tales discursos, mantenidos en voz alta y con los ojos abiertos, fueron interpretados por los testigos como auténticos sermones, y «cuando la enferma escuchó esta palabra y contempló su éxito en los húmedos ojos de los emocionados oyentes, sin pretender engañar a otros, se imaginó que era capaz de predicar» ${ }^{27}$, llegando a hacerlo incluso en los períodos de salud, extendiéndose a lo largo de una hora u hora y media. Los más ingenuos - prosigue el religioso - comenzaron a pensar que era un ángel o el espíritu de Dios quien hablaba por su boca; que anunciaba «un nuevo Evangelio del corazón ${ }^{28}$; y, lo que era más peligroso, que nunca habían escuchado nada tan hermoso y convincente de labios de un clérigo.

En este punto hay que señalar algo que permitirá comprender mejor la sensibilidad de los oyentes a los mensajes de Friederike. Nos encontramos, como queda dicho, en un pueblo de los Montes Metalíferos, en Sajonia, es decir, en pleno corazón de un movimiento religioso, el pietismo, que alcanzó su mayor expresión en el siglo XVIII, pero que aún impregnaba los corazones en el XIX, hasta el punto de que se le considera una de las raíces de la sensibilidad

27 KIESER, D.G. (1820 a), 53.

28 Ibid. 
romántica. Su capital intelectual estaba, o había estado en el siglo anterior, en la ciudad universitaria de Halle, no muy lejos de los Erzgebirge. También próxima a Johanngeorgenstadt se encuentra la localidad de Herrnhut, sede de un movimiento espiritual de corte pietista, heredero directo del de los «hermanos moravos», procedente de la vecina región checa de este nombre ${ }^{29}$ que, al menos como patrimonio histórico, pervive en la actualidad, y que tuvo gran pujanza en el período que nos ocupa. Y el pietismo es una concepción intimista y sentimental de la religión. Si es cierto, como es tópico reconocer, que algunos románticos luteranos se convirtieron a la fe católica por considerarla menos fría e intelectual, no lo es menos que muchos no tuvieron que hacerlo gracias a su orientación pietista. Creo que este ambiente espiritual resultó determinante para que los habitantes de Johanngeorgenstadt se inclinaran hacia esa «religión del corazón» que Friederike Erdmuthe Reinhold les proponía. Y algo así no podía dejar de resultar peligroso, por subversivo, para la Iglesia establecida, especialmente si el público declaraba que nunca había escuchado algo tan hermoso de labios de un pastor.

Poco tiempo después apareció en el curso del cuadro sonambúlico otro ingrediente aún más inquietante: la paciente, acostada, extendía lateralmente los brazos y miraba, con la cabeza inclinada, hacia uno de ellos, de modo que antes o después alguno de los circunstantes decía: «¡Parece Cristo en la cruz!», cosa que, con cierta preocupación, el sacerdote no puede sino confirmar. Además, en el contexto citado, esto fue interpretado como una profecía muda, y entre el pueblo llano empezó a circular la especie de que «la muchacha de Johanngeorgenstadt sería crucificada ${ }^{30}$. Como en el caso de la predicación, este eco popular dio alas a la imaginación de la paciente, que en sucesivos paroxismos reprodujo mímicamente la crucifixión tal como ella la concebía, lo que no deja de señalar el religioso. Extendía primero un brazo, y luego sus dedos se crispaban, como si estuvieran clavándola a la cruz; la acción se repetía con la otra mano y con los pies, que colocaba uno sobre el otro, como en las representaciones iconográficas más comunes de la pasión. Luego transcurrían unos diez minutos, que la gente comenzó a llamar «el cuarto de hora crucificado», tras de los cuales era «desclavada» y permanecía un rato quieta "para que sus heridas fueran untadas con bálsamo» ${ }^{31}$, como más tarde explicó.

La casa del alcalde zapatero se convirtió en un lugar de peregrinación, pues cada vez más gente creía que había aparecido una nueva Salvadora, en-

\footnotetext{
29 Sus miembros aparecen nombrados como «hernutas» (gentilicio) en textos en español.

30 KIESER, D.G. (1820 a), 55-56.

31 KIESER, D.G. (1820 a), 56-57.
} 
viada por el mismo Dios. Aún más - y tal vez sea éste un signo precoz de los tiempos que se por entonces despuntaban - muchos, o tal vez muchas, pensaron que se trataba de una Salvadora de las mujeres ${ }^{32}$. Llegada esta situación las autoridades tomaron cartas en el asunto y llamaron al orden al zapatero, prohibiéndole bajo pena de arresto que permitiera el acceso a su vivienda a los peregrinos. No contentos con esto, pusieron la casa bajo vigilancia los días en los que se esperaban los paroxismos, lo que no impidió que la gente siguiera acudiendo en masa. La situación alcanzó su punto de máxima tensión cuando la joven, en el curso de uno de sus paroxismos, anunció que en el curso de la Semana Santa sufriría punto por punto el suplicio de Jesucristo; que el Viernes Santo se vería crucificada entre dos ladrones y pronunciaría las palabras de Cristo en la cruz; y que por fin permanecería como muerta durante tres días, los mismos que aquél pasó en el sepulcro. Corrió el rumor, que el párroco desmiente, de que habría pedido ser realmente crucificada.

\subsection{Muerte y resurrección de la muchacha}

La Semana Santa de 1820 fue esperada con auténtica excitación por los moradores del territorio. El lunes 27 de marzo tuvo lugar uno de los paroxismos de la enfermedad, en el que Friederike anunció que desde el Jueves Santo repetiría uno por uno los pasos del Salvador, desde la Cena hasta el prendimiento en el Huerto de los Olivos. Confirmó su muerte de tres días después de la crucifixión, ordenando que, al menos por las noches, su cuerpo fuera cubierto con un lienzo. Anunció que el Viernes Santo no habría sol, o brillaría muy poco - en consonancia con el oscurecimiento referido en los evangelios- y que resucitaría el domingo a las seis de la mañana. Conviene hacer notar que la joven emplea las palabras «muerte» - Tod - y «resurrección» - Auferstehung - y no parece hacerlo en un sentido alegórico.

El jueves, acompañada por su hermana gemela, comulgó, y luego tomó dos tazas de café y un panecillo; su única comida del día, lo que no es extraño pues, según refiere ahora el pastor, durante su enfermedad había comido siempre muy poco. Se retiró después a su casa, que estaba «asediada» por una muchedumbre de creyentes y curiosos, y se recluyó en su habitación junto con «sus más celosos discípulos», dispuestos a representar hasta el final los papeles secundarios en esta especie de auto sacramental fuera de la ley. El

32 KIESER, D.G. (1820 a), 57-58. 
primer acto consistió en el lavado de los pies de los apóstoles, en el que la muchacha «ayudó» a Jesús, pidiéndole al acabar que se llevara la jofaina para que ella pudiera acostarse. La escena tuvo lugar a las seis de la tarde. Luego Friederike se acostó y permaneció tranquila hasta las 12. Entonces comenzó la crucifixión. Hasta las tres de la madrugada la joven sufrió las más espantosas convulsiones. En algún momento hizo gestos como de estar tragando algo con repugnancia, lo que de inmediato fue interpretado como efecto de la esponja empapada en hiel que, según el relato evangélico, se acercó a los labios de Jesús en la punta de un palo cuando dijo tener sed. A punto de dar las tres pronunció las palabras: «¡Padre, en tus manos encomiendo mi espíritu!» y «todo se ha consumado», y cayó en un profundo sueño magnético que, de no ser por la observación de los movimientos respiratorios del tórax y la palpación del pulso, anormalmente acelerado - 84 pulsaciones por minuto-, habría producido la impresión de la muerte.

Ante el eco que el caso estaba despertando se puso en marcha de inmediato una investigación judicial, encomendada a una comisión formada por un juez, dos médicos y un boticario. Ante testigos exploraron a la joven, utilizando para ello sustancias de olor desagradable, agujas y clavos, sin conseguir la menor respuesta, lo que les confirmó que la enferma se encontraba sumida en un profundo sueño magnético, en un estado que denominaron «asfixia». Así permaneció hasta las doce de la noche del sábado, declarándose entonces un intenso cuado de calambres que el Dr. Gruber intentó sin éxito aliviar con pases magnéticos durante seis horas, hasta que, tal como Friederike había anunciado, a las seis en punto resucitó. Todo esto, según el relator, fue presenciado por unas doscientas personas. Seguramente se trató de algunos privilegiados - autoridades locales, familiares... - pues según consta en algunos lugares del texto la plaza de la localidad estaba llena de curiosos y hubieron de tomarse medidas policiales para garantizar el orden.

Tenemos que lamentar, como el propio Kieser, editor de esta historia en el Archiv, no disponer de más información relativa al estado de salud de la joven. A la conclusión de ambos informes parece que tanto el sacerdote como el médico la dan por curada, aunque susceptible aún a desmayos y cefaleas, a menudo propiciadas por los cambios de tiempo. Da la impresión de que una vez realizada esa proeza que representa la escenificación de la pasión de Cristo la muchacha ha alcanzado un objetivo difícil de superar y tal vez razonablemente satisfactorio para ella. Regresa, desde luego, a sus labores de encaje, que había tenido que abandonar al sufrir su «enfermedad magnética», pues la proximidad de objetos metálicos desencadenaba las convulsiones. Pero la que regresa ya no es —o no es solamente— Friederike Erdmuthe, la hija del zapa- 
tero - o del alcalde - Reinhold, sino la muchacha maravillosa de Johanngeorgenstadt ${ }^{33}$.

Llegado a este punto el lector podría preguntarse qué tiene que ver este caso con el espiritismo, pues en el restricto sentido que el término ha alcanzado entre nosotros parecería no poder aplicarse a la historia recogida por Kieser; pero es él mismo quien nos da la repuesta en otro de sus trabajos para el $\mathrm{Ar}$ chiv: uno de los resultados de lo que denomina «sonambulismo magnético local» serían «las visiones de espíritus, demonios, ángeles buenos o malos, incluso del mismo diablo, así como de la persona del Salvador y de Dios mismo» ${ }^{34}$. Dentro del abigarrado mundo de los visionarios, al menos para uno de los más serios estudiosos del magnetismo animal, es lo de menos que el objeto de la visión sean los espíritus - por antonomasia, los de los difuntos-, los ángeles o Dios mismo. Cabe decir que también para el público dicho objeto es secundario, pues lo esencial es el descubrimiento de que se puede entrar en comunicación con otro mundo, hasta entonces sumido en el silencio. Así, del mismo modo que muchos pobladores de la zona minera de Sajonia se sintieron «magnéticamente» atraídos hacia Johanngeorgenstadt en la Semana Santa de 1820, otros muchos se vieron arrastrados hacia Suabia pocos años después; y en caso de no poder desplazarse, acudieron en masa a las librerías para hacerse con los extraordinarios relatos publicados por otro médico y magnetizador: Justinus Kerner.

\section{Dos Videntes De JustinUs KeRNER}

A continuación me ocuparé de dos célebres casos —uno de ellos celebérrimo - en los que, en desigual medida, intervino el médico y magnetizador suabo Justinus Kerner. En el primero, el de la famosa Vidente de Prevorst, Friederike Hauffe, la enfermedad está presente desde el comienzo y parece

33 Esta conclusión, que tan someramente acabo de exponer, es análoga a la tesis sostenida de manera más amplia por MoNCO, B. (2004). «Demonios y mujeres. Historia de una transgresión». En: TAusiet, M.; Amelang, J (Eds.) (2004). El Diablo en la Edad Moderna. Madrid, marcial Pons, 187-210. En este trabajo se estudia el caso de las endemoniadas del convento de San Plácido (Madrid, 1623). Como en el caso de Friederike Reinhold, en éste destaca la asunción por las monjas de roles masculinos dotados de valor salvífico, doctrinal y jerárquico (p. ej., los apóstoles).

34 KIESER, D.G. (1820 b). «Daemoniaca, aus ältern Schriften ausgezogen, und zur physiologischen Deutung mit ähnlichen magnetischen Erscheinungen in Verbindung gesetzt». Archiv für den thierischen Magnetismus, 8 (1), 1-47, p. 2. 
condición necesaria para la aparición de las facultades paranormales en la paciente. En el segundo, el de «la muchacha de Orlach», los fenómenos paranormales comienzan a producirse en ausencia de síntomas somáticos, de manera que la posibilidad de una enfermedad subyacente se plantea más tarde, y sólo para intentar explicar dichos fenómenos de manera «natural». En todo caso, en el relato que sobre este caso escribe Justinus Kerner esta hipótesis apenas tiene cabida pues, a raíz de sus experiencias previas con la Vidente de Prevorst, parece convencido de la existencia de un mundo de espíritus que puede infiltrarse en el nuestro. Así, en esta ocasión, la enfermedad, si la hubiere, sería expresión de «fenómenos cacodemónico-magnéticos», es decir, de fenómenos magnéticos producidos por un demonio malvado ${ }^{35}$. En fechas recientes ambos casos han sido interpretados como cuadros histéricos ${ }^{36}$, interpretación que asumo con todas las cautelas que impone el diagnóstico retrospectivo.

\subsection{La Vidente de Prevorst.}

Comencemos por el primero desde el punto de vista cronológico, el de la Vidente de Prevorst. Friederike Hauffe, una joven nacida en un villorrio rural

35 Esto es lo que significa kakodaímon. Existirían también agathodaímones, es decir, demonios - espíritus- buenos, que ejercen como Schutzgeister — espíritus protectores-. En la demonología de Kerner - que no es sólo suya, sino que procede del acervo popular y religioso- estos daimones son espíritus pertenecientes a personas muertas. Cfr. KERNER, J. (1835) Geschichten Besessener neuerer Zeit. Beobachtungen aus dem Gebiete kakodämonischmagnetischer Erscheinungen. $2^{\mathrm{a}}$ ed. aumentada, Karlsruhe, Braun. Al no disponer de esta edición cito a partir de una más tardía e incompleta: KERNER, J. (1927) Blicke eines Arztes in die Geheimnisse der Geisterwelt. Leipzig, Dienst am Volk, 24-35. Por cierto, parece más que probable que esta edición, con semejante título, se produjera al socaire del interés por el ocultismo a comienzos del siglo XX. El caso de «la muchacha de Orlach» forma parte de la obra original de Kerner; en su momento daré la referencia del texto utilizado.

Tanto la Vidente de Prevorst como la muchacha de Orlach tienen su Schutzgeist - con matices en el caso de la segunda, pues en su caso se trata de un alma en pena-, mientras que sólo en el caso de la muchacha existen Kakodaímones, por lo que el suyo es, según Kerner, un auténtico caso de posesión.

36 GrÜSSER, O. J. (1987). Justinus Kerner 1786-1862. Arzt-Poet-Geisterseher. BerlinHeidelberg-New York, Springer, 210, 214, 221, 223. GlatZEL, J. (1990). «Die Seherin von Prevorst —gelesen als eine psychiatrische Krankheitsgeschichte». En. SсHOTT, H. (Hrsg.) (1990), 411-421. HAMANAKA, T. (1990) «Justinus Kerners Beitrag zur Psychopathologie des Doppelgängers. Zur Forschungsgeschichte des Doppelgängers und verwandter Phänomene». Ibid., 376-392. Pero la hysteria no es el único diagnóstico aplicado, especialmente a la Vidente de Prevorst. Cfr. SCHOTT, H. (1986), 87. 
en la Alemania del Sur, destinada a llevar una vida idéntica a la de generaciones y generaciones de mujeres nacidas en ese contexto, entra de súbito en la historia local, y muy pronto en la de Alemania, para terminar formando parte, en alguna medida, de la historia universal, gracias a su extraña enfermedad ante la que se estrellan todos los intentos de tratamiento conocidos, especialmente los académicos. Quien terminará siendo su médico hasta el fin de sus días, Justinus Kerner, se verá obligado a cambiar sus opiniones y actitudes primeras frente a una enferma que parece saber más que él sobre la enfermedad que sufre - lo cual, como ya se ha señalado, no constituye una rareza en el mundo del magnetismo animal-, si es que se trata de una enfermedad; pues aunque sufre y su salud se deteriora de manera temible, ella misma no vive esa situación como algo negativo, ni mucho menos morboso. Además su paciente pronto parece estar en condiciones de ilustrarle acerca de ese gran tema de la Naturphilosophie romántica: el «lado nocturno» de la ciencia natural. Pero comencemos por el principio ${ }^{37}$.

Coincidiendo con el momento de formalizar el compromiso con un novio buscado por la familia, práctica habitual en el entorno rural, se produjo el fallecimiento de un anciano sacerdote, especie de figura paternal a quien la paciente dice haberse hallado muy vinculada. En el entierro del religioso, ante su tumba, la joven de 19 años sintió que desaparecía la «inexplicable» melancolía que había experimentado los días precedentes, y que comenzaba su verdadera vida espiritual. Esta lectura positiva contrasta con la que realiza la familia, pues Friederike empezó a sufrir los primeros síntomas de su enfermedad - fiebre, calambres torácicos, asma-, que requirieron la consulta del médico local. Meses después de tratamientos inútiles Friederike tuvo un sueño en el que se sentía impelida a levantarse de la cama, descubriendo en ella el cadáver del pastor, amortajado. Siguió soñando que escuchaba en la habitación contigua las voces de su padre y de dos médicos que hablaban acerca de ella, de una enfermedad que padecía; y ella les gritaba: «¡Dejadme tranquila con este muerto que me cura! ¡Ningún médico puede curarme!». Luego sintió como si quisieran arrancarla del lado del cadáver, cuya frialdad le producía un efecto salutífero, y volvió a hablar: «iQue bien me siento junto a este muerto! ¡Ahora me curaré del todo!» ${ }^{38}$.

37 KERNER, J. (1829). Die Seherin von Prevorst. Eröffnungen über das innere Leben des Menschen und über das Hereinragen einer Geisterwelt in die unsere. Utilizaré la edición de Raimund Pissin: Kerner, J. (1998) Werke. II Bd. Hildesheim-Zurich-New York, Georg Olms (Reprint de la edición de 1914). El texto sobre la Vidente se encuentra en el segundo volumen de esta edición (pp. 13-245) y mantiene a su vez la división en dos partes, a las que se refiere la numeración en romanos que utilizaré en las citas.

38 KERNER, J. (1998), I, 43. 
Resulta evidente la intención de la paciente de «morir» para la vida que otros habían diseñado para ella y renacer a esa «vida espiritual» de la que puede por fin ser protagonista. No llevaré más lejos mi interpretación, pues no es ese mi objetivo: Simplemente creo poder afirmar que en el planteamiento, seguramente inconsciente, de Friederike, la enfermedad, especialmente en el marco del magnetismo animal, a la sazón de moda en Alemania, le concede la libertad que necesita para, aun cuando sea pagando un alto precio, diseñar su propia vida. «Esta es la vida que quiero tener», parece decirles a su padre y a los médicos en el sueño referido. En cierto sentido se trata de un golpe de autoridad; y esa autoridad va a serle reconocida por el más capacitado de sus terapeutas, Justinus Kerner, que la acogerá en su casa ${ }^{39}$ durante dos años y medio, en principio para intentar devolverle la salud, pero a la larga para aprender de ella mucho de cuanto ignora acerca de ese Geisterwelt de cuya existencia, como cristiano, está convencido ${ }^{40}$.

A pesar de lo sostenido por la paciente en el episodio referido, lo cierto es que no se produjo nada semejante a una curación, sino más bien todo lo contrario. Los síntomas - calambres, convulsiones, pérdida de conciencia, anorexia - fueron agravándose, alternándose con breves períodos de recuperación coincidentes con dos embarazos seguidos de partos difíciles, y la paciente entró en un estado de emaciación que hacía temer por su vida. Llegó a perder todos los dientes, seguramente como resultado de un cuadro de escorbuto, a juzgar por la descripción de sus encías tumefactas y sangrantes. Fue en este momento cuando se decidió consultar al localmente célebre médico municipal de Weinsberg, Justinus Kerner, de quien era sabido que llegaba a albergar en su propia vivienda, la llamada Kernerhaus, a los pacientes más necesitados de su celo profesional.

La enferma llegó a Weinsberg el 25 de noviembre de 1826. Kerner la describe como «una imagen de la muerte»: emaciada, incapaz de mantenerse de pie, sangrando por las encías desdentadas y necesitando recibir una o dos cucharadas de sopa — su único alimento — que tragaba difícilmente, cada tres o cuatro minutos, pues en caso contrario perdía el conocimiento o era presa de convulsiones. Cada día, a eso de las siete de la tarde, entraba en sueño magnético, en el curso del cual cruzaba primero las manos sobre el pecho mientras recitaba una plegaria silenciosa y luego extendía los brazos hacia

39 Más exactamente, en su casa durante algunos períodos de la enfermedad, y en una casa próxima en otros momentos, según se desprende del testimonio de su hijo Theobald. KERNER, Th. (1913). Das Kernerhaus und seine Gäste, Weinsberg, Justinus Kerner-Verein, 94-99.

40 Schотт, H. (1986), 87-93. 
delante, comenzando sus visiones, de las que hablaba con los ojos cerrados. El primer día intentó hablar de este modo con el médico, a lo que este se negó. Al despertar la Vidente, Kerner le explicó que no hablaría con ella en estado magnético. Le dijo que iba a intentar con ella «un tratamiento psíquico», orientado a reforzar su voluntad para que su cerebro volviera a tomar la dirección de su aparato digestivo. Como puede verse, la declaración de intenciones no puede ser más científica; pero esta pretensión de cientificidad de Kerner se verá muy pronto desbordada por unos fenómenos que nuestro médico, más sensible de lo que él mismo parece reconocer a los sorprendentes mensajes de la «vida magnética», no podrá controlar, viéndose más bien arrastrado por ellos a ese Geisterwelt ${ }^{41}$ que su obra va a entronizar, al menos entre sus seguidores. Los tratamientos, incluso en dosis homeopáticas, o bien no producían efecto o bien provocaban el contrario al deseado, mientras que el «médico interior» de la Vidente, como el propio Kerner llamará en adelante a su capacidad autodiagnóstica y de autoprescripción, no cesaba de dar indicaciones que nada tenían que ver con lo que se enseñaba en las facultades, y que a menudo provenían de los espíritus con los que entraba en comunicación, muy especialmente el de su abuela, al que considera su Schutzgeist ${ }^{42}$.

Para empezar Kerner debió resignarse a aplicar un tratamiento magnético, y a relacionarse con la paciente sobre todo en este estado. Esta concesión tuvo alguna repercusión favorable sobre el entorno de Frau Hauffe merced, muy probablemente, a su contenido simbólico. El tratamiento magnético consiguió que se alimentara algo mejor, y conviene no olvidar que, hasta ese momento, los familiares de la enferma no podían alejarse de ella más de tres o cuatro minutos, pues tenían que darle la cucharada de sopa correspondiente; en ese sentido la «transfusión magnética» ${ }^{43}$ vendría a representar una especie de pacto simbólico más tolerable para todos, pues el efecto de los pases —que, preferiblemente, tenían que ser realizados por sus más próximos parientes-

41 «Mundo de espíritus». Hago referencia al subtítulo del libro dedicado a la Vidente: «Manifestaciones acerca de la vida interior del ser humano y acerca de la infiltración de un mundo de espíritus en el nuestro».

42 Literalmente «espíritu protector», una figura muy frecuente en la literatura magnética - y en general en la espiritista — de esta época, frecuencia que deja en bastante mal lugar al tradicional «ángel de la guarda».

$43 \mathrm{Al}$ postular Mesmer la existencia de un «fluido», todas las metáforas empleadas para explicar el rapport magnético se mueven en torno a la idea de flujo de una cierta energía, que a veces se equipara a la eléctrica, pero que, sobre todo en el dominio de la literatura, se aplica más bien a «principios vitales», y muy especialmente a la sangre. Cfr. BARKHOFF, J. (1995), 86-92, 200-201. 
resultaba ser más duradero que el de la cucharada de sopa. Pero Kerner también tenía que magnetizarla, de manera que, cuando se veía obligado a salir al campo para visitar a sus pacientes de caseríos remotos, magnetizaba a su hijo Theobald para que éste a su vez magnetizara, cuando fuera necesario, a la Vidente. Lo sabemos por el testimonio del propio Theobald en sus interesantes memorias de infancia y juventud tituladas La casa Kerner y sus huéspedes ${ }^{44}$.

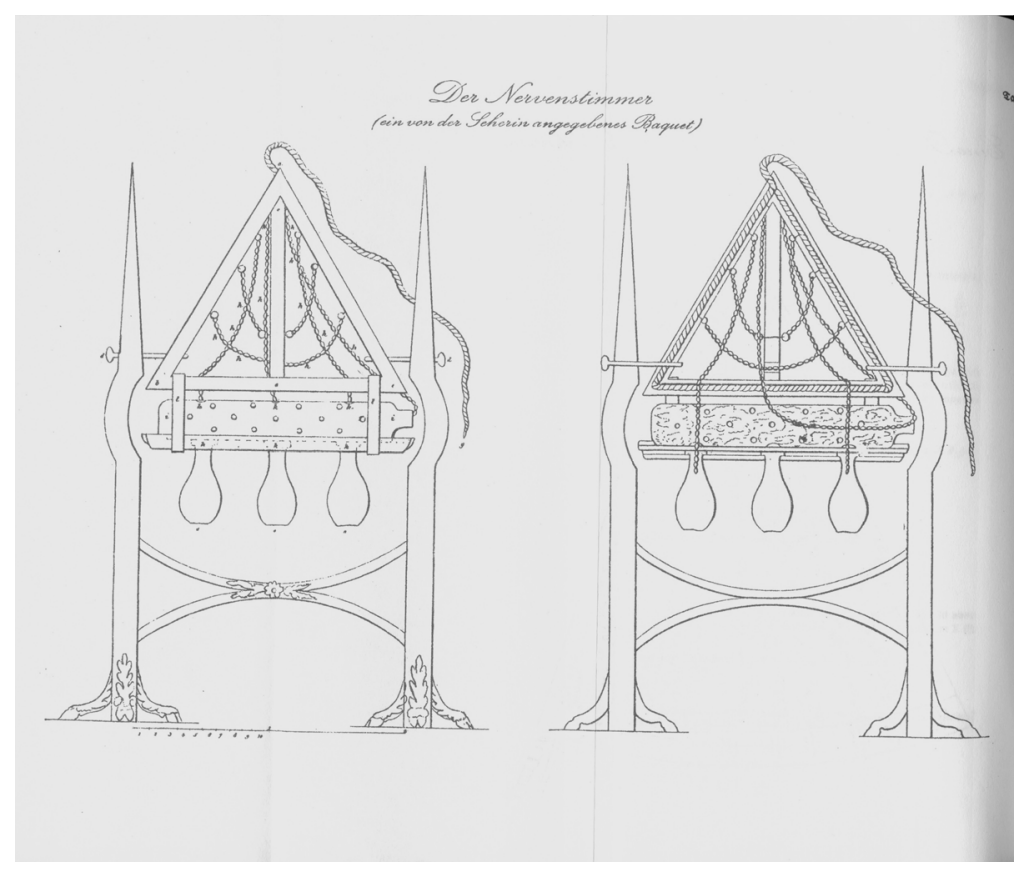

Croquis del Nervenstimmer realizado por Kerner bajo las indicaciones de la Vidente. Sobre éste se construyó el aparato que aún se conserva en la Kernerhaus (Weinsberg).

La sumisión de Kerner a su guía hacia el Geisterwelt llegó a ser casi absoluta. No se arredró ante la construcción de una fantástica variante del baquet magnético, diseñado por la Vidente y por ella denominado Nervenstimmer — algo así como «afinador de los nervios» (v. fig.) —, que le producía, según su propio testimonio, algún alivio. Y no se limitó a dejarse conducir por ella: en varias

44 KERNER, Th (1913), 96-97. 
ocasiones permitió que tratara a otros que acudían a la Vidente en demanda de sus singulares dotes. El caso más señalado fue el de la Condesa von Maldeghem, del que Kerner da puntual cuenta en su obra, que se zanjó con una cura mitad mágica, mitad religiosa a la que asiste con un respeto venerativo y que sin duda provocó serios ataques de nervios a algunos médicos contemporáneos de nuestro autor, entre ellos nuestro ya conocido Kieser ${ }^{45}$.

Friederike Hauffe permaneció en Weinsberg al ciudado de Justinus Kerner y su familia hasta el 5 de mayo de 1829, es decir, dos años y medio. Durante este tiempo Kerner presenció numerosas muestras de clarividencia que hicieron de él un auténtico converso. Puede considerarse, sin exageración alguna, que la fecha de la llegada de la Vidente a la Kernerhaus señala el nacimiento del espiritismo, pues la obra en la que el médico romántico reseñará sus experiencias proclama «la infiltración de un mundo de espíritus en el nuestro» ${ }^{46}$; una creencia que, al final de sus días, cristalizaría en una curiosa obra de creación pictórico-poética, las Kleksografias ${ }^{47}$, y que en el texto sobre la Vidente le mueve a transcribir con la mayor precisión los signos del «lenguaje interior» mediante el que su paciente y maestra habla con los espíritus, esforzándose incluso en encontrar parentescos con los idiomas copto, árabe y

45 Gauld, A. (1992), A history of hypnotism. Cambridge University Press, 158; BREDNOw, W. (1970). Dietrich Georg Kieser. Sein Leben und Werk. Wiesbaden, Steiner, 87. La crítica a la que me refiero, de la que el propio Kieser da cuenta en una nota al pie insertada en uno de sus textos dedicados al análisis de casos, formaba parte de un estudio más extenso, publicado en latín, titulado Singularis dementiae species in foemina daemonica wirtembergica illustratur, Jena, 1830. La parte correspondiente a la vidente se publicó traducida -mal- y sin permiso del autor en Berlin el año siguiente, con el título Über die eigenthümliche Seelenstörung der sogenannten Seherin von Prevorst. Cfr. KIESER, D.G. (1834). «Daemonomania in der Form der neueren Zeit». En: Klinische Beiträge, Leipzig, 258-351, pp. 295-296.

46 Cierto es, como ya he señalado, (v. n. 4) que el espiritismo propiamente dicho - es decir, el que se otorga este nombre-, entendido además como fenómeno de masas no surgirá hasta mediados de siglo en Francia, de la mano de Allan Kardec, y en parte como producto importado de los estados Unidos más que de Alemania. Cfr. EdELmAn, N. (2006), 65-77.

47 He publicado una edición bilingüe del álbum de kleksografías preparado por Kerner en 1857 y editado a título póstumo en 1890: JustinUs KERNER (2004). Kleksografías. Ed. de Luis Montiel. Barcelona, MRA. Sobre este tema, además del estudio preliminar a dicha edición, véase: Grüsser, O.J. (1987), 320-321; Hofmann, K. L.; Praeger, Ch. (1986). «Bilder aus Klecksen. Zu den Klecksographien von Justinus Kerner». En: BERGER-FIX, A. (Hrsg.) (1986), 125-152. ArburG, H.G. v. (2001). «Dämonische Signaturen aus dem Tintenfass. Justinus Kerners Kleksographien und die 'Zufallsbilder' der Natur», en: ARBURG, H.G. v.; GAMPER, M.; STADLER, U. (Hrsg.). Wunderliche Figuren. Über die Lesbarkeit von Chiffrenschriften. München, Wilhelm Fink, 43-67. 
hebreo, pues Frau Hauffe asegura que ese idioma, que todo ser humano conserva en su interior, era el que se hablaba en los tiempos de Jacob.

En esta perspectiva, la muerte de la Vidente el 5 de agosto de 1829 no fue en modo alguno considerada un fracaso por Justinus Kerner. Al fin y al cabo había alcanzado la vida espiritual a la que tendía desde el momento en que tuvo la revelación de su existencia ante la tumba del pastor. Sus espíritus la acompañaron en el tránsito, anunciándole su muerte con tres días de antelación y confirmando su inminencia con esta frase, que en un momento de lucidez, reveló a su médico: «iya estás con nosotros!» ${ }^{48}$.

\subsection{La muchacha de Orlach}

En 1834 Kerner publicó un nuevo libro destinado a tener una resonancia comparable, al menos a nivel local, al dedicado a la Vidente: Historias de posesas de la época más reciente. Observaciones en el ámbito de los fenómenos cacodemónico-magnéticos ${ }^{49}$. Una de estas historias lleva por título «la muchacha de Orlach» y su éxito fue tan asombroso que al poco tiempo de aparecer la edición del libro de Kerner se publicó lo que hoy llamaríamos una «edición pirata» de dicho caso.

En el prólogo del citado libro el médico de Weinsberg declara haberse interesado por el fenómeno de la posesión a partir de sus experiencias con la Vidente de Prevorst, que le convencieron definitivamente de la existencia de un mundo de espíritus que, a través del magnetismo animal, puede infiltrarse en el nuestro. En consecuencia, acepta las doctrinas tanto de la Iglesia como de diversos médicos del pasado relativas a la real existencia de enfermedades producidas por la presencia en el interior del ser humano de malos espíritus (demonios, kakodaimones) o del mismo diablo ${ }^{50}$.

La protagonista de esta historia es la joven Magdalene Grombach, hija de un campesino de la pequeña localidad de Orlach, en Württemberg, cerca de la hermosa y pequeña ciudad de Schwäbisch Hall. En el momento en que sucedieron los hechos Orlach tenía alrededor de doscientos habitantes. Kerner

48 KERNER, J. (1998), II, 242.

49 Kerner, J. (1834). Geschichten Besessener neuerer Zeit. Beobachtungen aus dem Gebiet kakodämonisch-magnetisnh Erscheinungen. Karlsruhe, Braun. He utilizado la edición on line del Projekt Gutenberg: http://gutenberg.spiegel.de/kernerj/orlach/orlach.htm La paginación corresponde a la que aparece en la versión on line, en la que cada página tiene una extensión equivalente a 3-4 impresas.

50 V. n. 35. 
describe a Magdalene como activa y alegre, muy dedicada a los trabajos del campo, con escaso interés por la escuela y por la lectura, y particularmente sana pues, a sus veinte años, «no ha padecido ni la menor enfermedad infantil, ni convulsiones, ni lombrices, ni exantemas, ni congestiones sanguíneas, ni ha necesitado llevarse a la boca el menor medicamento» ${ }^{51}$. Nada, pues, hacía presagiar a comienzos de 1831 que unos acontecimientos turbadores que la tendrían como protagonista iban a desencadenarse sobre la hasta entonces tranquila casa de los Grombach. Después de algunos extraños, aunque inocentes fenómenos ${ }^{52}$, acaecidos en el establo - las vacas aparecen con las colas trenzadas sin que nadie pueda averiguar quién es el autor de la broma-, comienzan a desatarse pequeños incendios en el establo y en otras partes de la casa, igualmente atizados por mano invisible, o al menos desconocida. Incluso estando alerta los moradores de la casa Grombach son incapaces de descubrir al autor de las fechorías. Entonces Magdalene declara haber contemplado un fantasma en el establo: una figura femenina que, en sucesivas visitas, afirmará ser el alma en pena de una monja pecadora nacida en la misma fecha que Magdalene, aunque cuatrocientos años antes, y anunciará grandes desgracias a consecuencia de la inmediata aparición de otro fantasma, que en efecto no tarda en presentarse: un espíritu al que Magdalene denomina «el Negro» y que no siempre adopta figura humana, sino que a menudo se presenta bajo la de diversos animales y en una ocasión bajo la de un monstruo. También, en su afán tentador, puede adoptar la apariencia de algunos vecinos de la joven.

El Negro, que resulta ser el espíritu de un monje seductor y criminal, pretende inducir a la joven a hablar, a lo que ésta, siempre según los consejos de la monja, debe resistirse a cualquier precio, pues de lo contrario sucedería una catástrofe. Aunque, de hecho, la catástrofe sucederá antes o después, ya que, incluso respetando ese peculiar voto de silencio, el poder del Negro es tal que si la familia no se resuelve a demoler la vivienda y construirla de nuevo antes de una fecha concreta, el 5 de marzo del año siguiente, ésta perecerá pasto de las llamas.

Como era de esperar, lo primero que hizo la familia ante estas revelaciones fue llamar a consulta al pastor, que, tras contemplar las conversaciones de Magdalene con su interlocutora invisible, no pudo dejar de señalar que le admiraba la calidad del lenguaje religioso de que hacía ostentación, pues hasta entonces había sido una de sus discípulas menos aplicadas en la catequesis.

51 KERNER, J. (1834)., 1

52 Inocentes sólo en apariencia; pues Kerner señala que precisamente el trenzado por mano invisible de las colas de los animales se presenta como obra diabólica en un célebre tratado alemán de magia. KERNER, J. (1834), 1, n.1. 
Pidió a la joven que preguntara al espíritu por el motivo por el que no se manifestaba a nadie más, lo que hubiera constituido una garantía de su existencia y de la veracidad de sus advertencias, disipando la sospecha de que sólo se tratara, en palabras de Magdalene, de un engaño de su cerebro. Con tono de tristeza la monja le respondió que si decidiera manifestarse a un eclesiástico y le recitara una verdad de las contenidas en los Evangelios tampoco la creería hasta que lo viera con sus propios ojos. Le dijo igualmente que sabía que también otro clérigo había pedido recientemente a Magdalena que le describiera la materia de la que estaba hecha la aparición, y le indicó que le contestara esto: «mira un día al sol y dime luego de qué materia está hecho» ${ }^{53}$. Con estas dos respuestas la monja, o bien Magdalene, reducía a la nada las pretensiones de los eclesiásticos, pues las presentaba como meras reivindicaciones ilustradas, alejadas por tanto del ámbito en que se estaba dirimiendo la situación, puramente espiritual. Los clérigos, parece pensar el espíritu $-\mathrm{o}$ bien Magdalene-, se comportan de la misma manera en que podría comportarse un médico, o un jurista, o un físico, luego son incapaces de aportar nada valioso a favor del rescate del espíritu de la monja y de la integridad de los habitantes de la granja, amenazados por un peligro sobrenatural. Por otra parte, al comportarse como puros racionalistas traicionan su ministerio y a sus fieles, dejándolos en la estacada en el dominio que, hasta ese momento, era patrimonio de la Iglesia: el de lo sobrenatural. No puede extrañar que la reacción definitiva del espíritu de la monja ante estas pretensiones sea retirarse en silencio, entre sollozos.

El Negro se hizo presente por primera vez — desde luego, sólo para la muchacha- en el mes de julio, coincidiendo con el inicio de las duras labores de la cosecha. En la madrugada del primer día en que Magdalene salía a segar con su padre se le manifestó sucesivamente bajo la figura, simplemente engañosa, del mozo del vecino, y bajo las más atemorizadoras de un gato, un perro y una potranca, todos de color negro. En días sucesivos se presentó como una ternera y como un caballo negro decapitado que trotaba y saltaba en torno a la muchacha. Por fin se le apareció en figura humana, la de un hombre negro, sin cabeza en una ocasión y a menudo vestido como un monje, tentándola para que hablara y ofreciéndole dinero para que hiciera decir una misa católica en una localidad vecina, siendo todos los habitantes de Orlach luteranos ${ }^{54}$. Todo esto dio pie a que el pastor aconsejara a Grombach que llevase consigo

53 KERNER, J. (1834), 1

54 GehrTs, H. (1966). Das Mädchen von Orlach. Erlebnisse einer Besessenen. Stuttgart, Klett, 93. 
una biblia a las labores del campo, estrategia que se reveló completamente inútil. Por otra parte, dado que la muchacha resistía con éxito su acoso, el Negro decidió actuar de manera más radical: entrando en su cuerpo y produciéndole atroces sufrimientos, en forma de convulsiones, momento en que se solicita el socorro del ya célebre médico de Weinsberg.

Hay que señalar que el relato que Kerner hace de este caso es menos prolijo que el de la Vidente y notablemente más crédulo ${ }^{55}$. Posiblemente se siente justificado por la defensa que hace en las primeras páginas de las enfermedades debidas a posesión demoníaca; por eso mismo constituye un paso adelante en la marcha del magnetismo animal hacia el ocultismo, y seguramente eso es lo que explica la condición de best seller de su opúsculo a él dedicado; una condición de la que jamás gozaron los estudios más rigurosos de otros autores. Para él, Magdalene recibe realmente las visitas de ambos espíritus, y en el momento en que interviene en el caso la joven está, en su opinión, verdaderamente enferma. Las convulsiones que sufre en este período final de la historia son, según sus observaciones, resultado de la posesión por ambos espíritus, el positivo de la monja y el nocivo del Negro, situados respectivamente en el lugar simbólicamente correspondiente - derecha e izquierda - y luchando entre sí por el espíritu de la joven. Tal interpretación es, por otra parte, sugerida de manera ostensible por la mímica de la paciente.

Uno de los motivos de la convicción de Kerner sobre la realidad de la posesión viene dado por el hecho de que, cuando intentaba apaciguar los síntomas que se presentaban durante los cuadros convulsivos mediante pases magnéticos, «el demonio procuraba neutralizarlos con contrapases realizados a través de las manos de la joven» ${ }^{56}$. Esto no le conturbó en lo más mínimo pues, convencido del carácter «demónico-magnético» de la enfermedad de la muchacha, podía prescindir de todo tipo de medicamento, ya que podía contarse con la curación prometida por el buen espíritu para el día 5 de marzo.

En estas circunstancias al pobre Grombach no le queda otro remedio que ordenar la entera demolición de su granja y su ulterior reedificación, ceremonia simbólica donde las haya, y que sin duda implicaba un enorme sacrificio económico. A partir de este momento el espíritu oscuro atenúa su presión, incluso cambia de actitud para terminar realizando, por boca de la joven, una

55 En su exhaustivo estudio de este caso Heino Gehrts ha señalado, basándose en materiales de archivo locales, que en los citados conatos de incendio se descubrieron en algunos rincones pequeños dispositivos nada «espirituales», como por ejemplo bolsitas con carbones al rojo. GEHRTS, H. (1966) 8, 16.

56 KERNER, J. (1834), 3 
confesión pública de los pecados que han hecho de él un alma en pena, en lo que le precederá el espíritu de su rival y antigua amante, la monja. Las confesiones de ambos espíritus, especie de novela gótica salpicada de seducciones, traiciones y asesinatos en el claustro renacentista en el que, supuestamente, vivieron su existencia pecadora quienes visitaban en espíritu a Magdalene, parecieron verse confirmadas por el descubrimiento de huesos humanos, algunos de ellos infantiles, bajo un antiguo muro que formaba parte de la casa; y la autenticidad de cuanto había ocurrido, por el hecho de que la muchacha de Orlach recuperó la salud, no volviendo a mostrar, en palabras de Kerner, «un solo signo de su antiguo estado demónico-magnético» ${ }^{57}$.

\section{REFLEXIÓN FINAL}

Las tres historias referidas, caracterizadas por una fenomenología somática muy semejante, comparten otro denominador común: la visión de espíritus por las pacientes. Este será sin duda el hecho más relevante para su entorno, siendo la enfermedad una presencia desgraciadamente habitual en las comunidades humanas, y no sólo en ellas. Entrenados por una larga experiencia que sus médicos no podían aún poseer, podemos pensar que con sus síntomas, estas mujeres habrían intentado llamar la atención de sus circunstantes, bien por considerarlos sordos a otro tipo de llamadas, bien porque el mensaje que deseaban transmitir era de algún modo heterodoxo, o bien por ambas razones. Esta llamada de atención podía ser también una petición de ayuda — lo que resulta menos claro en el caso de la Vidente de Prevorst-.

Pero el suyo no es un caso aislado; en los textos de la época podemos encontrar profusión de historias semejantes, lo que hizo decir a G. H. von Schubert, precisamente interpretando desde un punto de vista histórico la aparición del magnetismo animal, que en un tiempo como era aquél en el que habían nacido los románticos, dominado por el pensamiento materialista, en el que lo espiritual corría el riesgo de desaparecer, el alma dejó de nuevo oír su voz ${ }^{58}$. De este modo, los gritos de las histéricas - los audibles y los inaudibles: los gritos del cuerpo- y las revelaciones de las videntes no serían sino otras tantas manifestaciones del dolor del alma de una época. De una época que en

57 KERNER, J. (1834), 4.

58 Schubert, G. H. v. (1850). Die Geschichte der Seele, II, Stuttgart, Cotta (reprint Hildesheim, Georg Olms, 1961, a partir de una edición de 1877), 24-25. En todo caso se trata, trata, a juzgar por el prólogo del autor, de una reedición de la sexta (1850). 
una parte de sí misma - la mujer, o mejor, ciertas mujeres, pero también ciertos artistas - se siente enferma, y en otra parte aún más extensa - los crédulos, médicos o no, en estas nuevas profetisas y mesías - manifiesta sin saberlo los síntomas de esa enfermedad del alma. Con el magnetismo animal, y también con el espiritismo, una época intentó, entre otras cosas y sin duda de manera inconsciente, curarse a sí misma de un mal que no sabía reconocer ${ }^{59}$. Lamentablemente, la terapéutica fue generalmente tomada por un nuevo tipo de enfermedad de la razón, al ser incapaz la mayoría de entender la críptica frase de Hölderlin: «allá donde está el peligro crece también lo que nos sal$v a \gg$. No corrían buenos tiempos para esta homeopatía metafísica.

Fecha de recepción: 11 de junio de 2006

Fecha de aceptación: 5 de septiembre de 2006

59 Tomo la idea de Michel de Certeau pues, aunque él la plantea para otra época y otro lugar (Francia, siglo XVII) creo que puede aplicarse perfectamente a la que aquí se estudia: «Las diablerías son a la vez síntomas y soluciones transitorias» CERTEAU, M. (1990). La possession de Loudun. Paris, Gallimard, 15. 